\title{
Measurement of blood calprotectin (MRP-8/MRP-14) levels in patients with juvenile idiopathic arthritis
}

\author{
Jaryna Bojko \\ Lviv Regional Council Public Institution "Western Ukrainian Specialized Children's Medical Centre”, Ukraine \\ Department of Clinical Immunology and Allergology, Danylo Halytsky Lviv National Medical University, Ukraine
}

\begin{abstract}
Objectives: The aim of the investigation was to compare blood calprotectin (MRP8/14, S100A 8/9) levels in patients with systemic-onset, polyarticular, RF-negative and oligoarticular subtypes of juvenile idiopathic arthritis (JIA), and to explore links between blood calprotectin levels and clinical and laboratory markers of JIA activity.

Material and methods: Measurement of calprotectin in blood serum was performed in 160 patients with JIA followed up at Lviv Regional Council Public Institution "Western-Ukrainian Specialised Children's Medical Centre". Seventeen patients with systemic-onset JIA (sJIA) and 49 patients with other JIA subtypes (RF-negative polyarthritis and oligoarthritis) in the active phase of the disease were included in this study. Determination of calprotectin levels in blood serum was performed using EK-MRP8/14 Buhlmann Calprotectin reagents (Buhlmann, Switzerland) by the ELISA method.

Results: The results of the investigations showed that blood calprotectin levels were higher in patients with systemic-onset subtype of the disease (median 13,800 ng/ml), and differed significantly from levels in healthy children (median $1,800 \mathrm{ng} / \mathrm{ml}, p=0.00002$ ), levels in patients with articular subtypes of JIA (median 2,700 ng/ml, $p=0.000008$ ), and patients with RF-negative polyarthritis (median 3,800 ng/ml, $p=0.003226$ ) and oligoarthritis (median 2,500 ng/ml, $p=0.000009$ ). The highest blood calprotectin levels were found in patients with newly diagnosed $s$ JIA, the median being 32,500 ng/ml (range: 13,800-177,000 ng/ml). Direct correlations were found between blood calprotectin and JADAS 27 activity score $(p=0.000009)$, ESR $(p=0.000079)$ and CRP $(p=0.000058)$. Conclusions: Blood calprotectin level is one of the measures that can be used to confirm the diag nosis of sJIA and to monitor the disease activity and therapy effectiveness.
\end{abstract}

Key words: juvenile idiopathic arthritis, biomarkers, MRP-8/MRP-14, blood calprotectin.

\section{Introduction}

In recent years special attention in diagnostics of systemic-onset juvenile idiopathic arthritis (sJIA) started to be paid to determination of levels of S100A8 (also called MRP-8) and S100A9 (also called MRP-14) proteins, which are secreted at the time of neutrophil and monocyte activation, and have a common name - blood calprotectin [1-5]. Blood calprotectin (MRP-8/MRP-14) is a complex that stimulates endogenous Toll-like receptors on cells, leading to production of anti-inflammatory cytokines.
According to many studies conducted over recent years, S100A8 and S100A9 proteins are recommended for use in differential diagnostics of SJIA and fevers of unknown origin (infectious, oncologic), for subclinical inflammation detection and for therapy response control. Measurement of blood calprotectin level may help in predicting the JIA subtype, which determines the choice of further therapeutic tactics [6-7].

The aim of this study was to compare blood calprotectin (MRP8/14, S100 8/9) levels in patients with systemic-onset, polyarticular, RF-negative and oligoarticular

\section{Address for correspondence:}

Jaryna Bojko, Lviv Regional Council Public Institution “Western Ukrainian Specialized Children's Medical Centre”, Lviv, Ukraine,

e-mail: jboyko@ukr.net

Submitted: 22.12.2016; Accepted: 6.01.2017 
subtypes of JIA, and to investigate correlations between blood calprotectin levels and clinical and laboratory markers of JIA activity.

\section{Material and methods}

Measurement of calprotectin in blood serum was performed in 160 patients with JIA followed up at the Lviv Regional Council Public Institution "Western-Ukrainian Specialised Children's Medical Centre”, among them 17 patients with SJIA and 49 patients with polyarthritis with negative rheumatic factor and oligoarthritis in the active period of the disease. Diagnosis of JIA was made according to ILAR classification criteria, Durban, 1997, Edmonton, 2001 [8]. The control group comprised 10 healthy children ( 4 boys and 6 girls) aged between 7 months and 17 years.

Bioethics committee has made agreement for this research work. Determination of calprotectin levels in blood serum was performed using EK-MRP8/14 Buhlmann Calprotectin (MRP-8/14 (S100A 8/9) reagents, Switzerland, by the ELISA method. The tests were performed at "Intersono" laboratory, Lviv.

Statistical analysis was performed using "STATISTIC 8.0" software package. Distribution of quantitative measures in the group is presented as the median (minimum-maximum) [lower-upper quartiles], because distribution of parametric data in the samples was non-Gaussian (validation using Shapiro-Wilk criteria). Comparison of rank and parametric data was performed using Mann-Whitney criteria, which needs no check for normality of distribution and is suitable for comparison of small samples.

\section{Results of the study}

Characteristics of JIA patients, in whom blood calprotectin level was determined, are presented in Table I. Out of 160 patients, 87 had active disease, while 73 were in remission or had an inactive disease. 102 patients received immunosuppressive therapy with methotrexate, 3 with sulfasalazine, 13 with adalimumab, 14 with tocilizumab, and 7 with etanercept.

Seventeen patients with sJIA and 49 patients with other IIA subtypes (polyarthritis with negative rheumatic factor and oligoarthritis) in the active period of the disease entered this study (Table II).

Among patients with systemic-onset arthritis, 6 were boys and 11 girls, with a median age at disease onset of 2.5 years (range $1-12$ ) and median disease duration of 4 years (range: $0.4-6)$. Median number of joints involved was 2 (range: 0-19). Median JADAS 27 activity score was 10 (range: 0-35).
Among patients with seronegative polyarthritis, 2 were boys and 10 girls. Median age at disease onset was 5.5 years (range: $2.8-11$ years) with a median disease duration of 1 year (range: $0.02-6$ years). Median number of joints involved was 4.5 (range: 0-28). Median JADAS 27 activity score was 6.5 (range: 0-36). Thirty-seven children with oligoarthritis were investigated (11 boys and 26 girls). Median age at disease onset was 3 years (range: 1-15.8 years) with a median disease duration of 2.5 years (range: $0.1-14.5$ years). Median number of joints involved was 1 (range: 0-8). Median JADAS 27 activity score was 5 (range: 0-25).

Blood serum calprotectin levels were higher in patients with systemic-onset disease (median 13,800 ng/ml), being significantly different from values of healthy children (median 1,800 ng/ml, $p=0.00002$ ), patients with articular forms (median 2,700 ng/ml, $p=0.000008$ ), patients with RF-negative polyarthritis (median 3,800, $p=0.003226$ ) and oligoarthritis (median 2,500 ng/ml, $p=0.000009$ ).

The highest calprotectin values were found in children with newly diagnosed SIIA, the median being $32,500 \mathrm{ng} / \mathrm{ml}$ (range: 13,800-177,000 ng/ml). This index

Table I. Features of JIA patients tested for blood calprotectin levels in blood serum

\begin{tabular}{|c|c|}
\hline Total number & 160 \\
\hline Gender (m/f), numbers & $54 / 106$ \\
\hline \multicolumn{2}{|l|}{ JA subtypes, numbers } \\
\hline systemic & 24 \\
\hline polyarthritis, $\mathrm{RF}^{-}$ & 28 \\
\hline polyarthritis, $\mathrm{RF}^{+}$ & 6 \\
\hline enthesitis-related arthritis & 29 \\
\hline oligoarthritis & 72 \\
\hline psoriatic & 1 \\
\hline $\begin{array}{l}\text { Age at time of investigation, years, me- } \\
\text { dian (min.-max.) [lower-upper quartiles] }\end{array}$ & $\begin{array}{c}10.0(1.0-32.0) \\
\quad[5.0-14.0]\end{array}$ \\
\hline $\begin{array}{l}\text { Age at disease onset, years, median } \\
\text { (min.-max.) [lower-upper quartiles] }\end{array}$ & $\begin{array}{l}5.0(0.6-17.0) \\
{[2.5-10.3]}\end{array}$ \\
\hline Disease in active phase, numbers & 87 \\
\hline \multicolumn{2}{|l|}{ Remission, numbers } \\
\hline medication-induced & 64 \\
\hline non-medication & 9 \\
\hline \multicolumn{2}{|l|}{ Therapy, numbers } \\
\hline adalimumab & 13 \\
\hline tocilizumab & 14 \\
\hline etanercept & 7 \\
\hline methotrexate & 102 \\
\hline prednisolone & 14 \\
\hline sulphasalazine & 3 \\
\hline
\end{tabular}


Table II. Clinical and laboratory data of patients with systemic-onset JIA, seronegative polyarthritis and oligoarthritis

\begin{tabular}{|c|c|c|c|}
\hline Parameters & $\begin{array}{l}\text { Healthy children } \\
\text { control group }\end{array}$ & $\begin{array}{l}\text { Group of children with } \\
\text { systemic-onset JIA }\end{array}$ & $\begin{array}{c}\text { Group of children with oligoarthritis } \\
\text { and } \mathrm{RF}^{-} \text {polyarthritis }\end{array}$ \\
\hline & \multicolumn{3}{|c|}{ median (min. - max.) [lower - upper quart.] } \\
\hline Number & 10 & 17 & 49 \\
\hline Gender, m/f & $4 / 6$ & $6 / 11$ & $13 / 36$ \\
\hline Age at onset, years & - & $2.5(1.0-12.0)[2.5-4.0]$ & $3.9(1.0-15.8)[2.0-8.0]$ \\
\hline Duration of JIA, years & - & $4.0(0.0-31.0)[0.4-6.0]$ & $2.0(0.02-14.5)[0.5-5.0]$ \\
\hline Number of joints involved & - & $2(0-19)[0-2]$ & $2(0-28)[1-2]$ \\
\hline JADAS 27 & - & $10.0(0.0-35.0)[8.0-20.0]$ & $6.0(0.0-36.0)$ [3.0-9.0] \\
\hline $\mathrm{ESR}, \mathrm{mm} / \mathrm{hr}$ & $\begin{array}{c}7.0 \\
(4.0-19.0) \\
{[5.5-12.8]}\end{array}$ & $\begin{array}{c}10.0(2.0-64.0)[5.0-43.0] \\
{ }^{* *} p=0.191740\end{array}$ & $\begin{array}{c}8.0(0.0-38.0)[5.0-14.3] \\
{ }^{*} p=0.073255 \\
{ }^{* *} p=0.983577\end{array}$ \\
\hline CRP, mg/l & $\begin{array}{c}3.3 \\
(0.4-8.4) \\
{[2.9-4.4]}\end{array}$ & $\begin{array}{c}8.0(6.0-48.0)[6.0-24.0] \\
{ }^{* *} p=0.000148\end{array}$ & $\begin{aligned} 6.0(0.0 & -36.0)[6.0-6.0] \\
{ }^{*} p & =0.011099 \\
{ }^{* *} p & =0.000896\end{aligned}$ \\
\hline WBC, $\times 10^{9} / 1$ & $\begin{array}{c}7.2 \\
(4.3-11.9) \\
{[5.6-9.2]}\end{array}$ & $\begin{array}{c}10.0(4.0-20.0)[6.0-11.5] \\
{ }^{* *} p=0.214848\end{array}$ & $\begin{array}{c}7.9(0.7-17.0)[6.0-10.0] \\
{ }^{*} p=0.232594 \\
{ }^{* *} p=0.635151\end{array}$ \\
\hline $\begin{array}{l}\text { Calprotectin, } \\
\times 10^{3} \mathrm{ng} / \mathrm{ml}\end{array}$ & $\begin{array}{c}1.8 \\
(1.0-2.7) \\
{[1.5-2.3]}\end{array}$ & $\begin{array}{c}13.8(3.1-177.0)[5.8-26.0] \\
{ }^{* *} p=0.00002\end{array}$ & $\begin{array}{c}2.7(0.4-49.5)[1.7-4.0] \\
{ }^{*} p=0.000008 \\
{ }^{*} p=0.051134\end{array}$ \\
\hline
\end{tabular}

${ }^{*} p$-in comparison with $s / I A,{ }^{* *} p-i n$ comparison with control

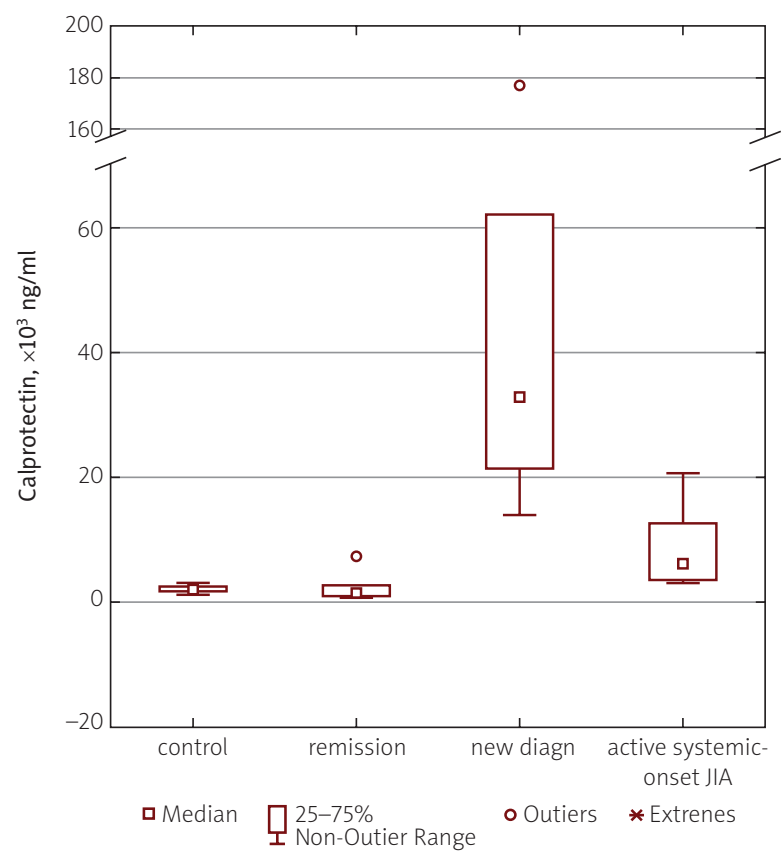

Fig. 1. Comparison of blood serum calprotectin levels in healthy subjects of the control group and patients with active sJIA, newly diagnosed sJIA and patient in remission phase. was significantly higher not only in comparison with systemic-onset arthritis patients in the inactive period (median 1,700 ng/ml, range: 600-7,100 ng/ml), but also in comparison with patients in the active period at the time of disease flare (median 6,000 $\mathrm{ng} / \mathrm{ml}$; range: $3,100 \mathrm{ng} / \mathrm{ml}$ up to $20,300 \mathrm{ng} / \mathrm{ml}$ ) (Fig. 1).

A study investigating the correlation of blood serum calprotectin levels in all patients with JIA in the active period of the disease with clinical and laboratory parameters of disease activity was performed. A direct correlation was found between calprotectin and JADAS 27 activity score $(p=0.000009)$, ESR $(p=0.000079)$ and $\operatorname{CRP}(p=0.000058)$ (Fig. 2-4).

\section{Discussion}

Systemic-onset JIA is a multifactorial auto-inflammatory disease, which manifests with arthritis, febrile spikes, erythematous rash, hepatosplenomegaly and serositis [9]. At disease onset usually just hectic fever is present, while symptoms of arthritis - the most important signs confirming the disease - are often absent. There are difficulties in diagnosis of systemic-onset arthritis in the initial phase of the childhood disease due to the need for differentiation not only with various JIA 


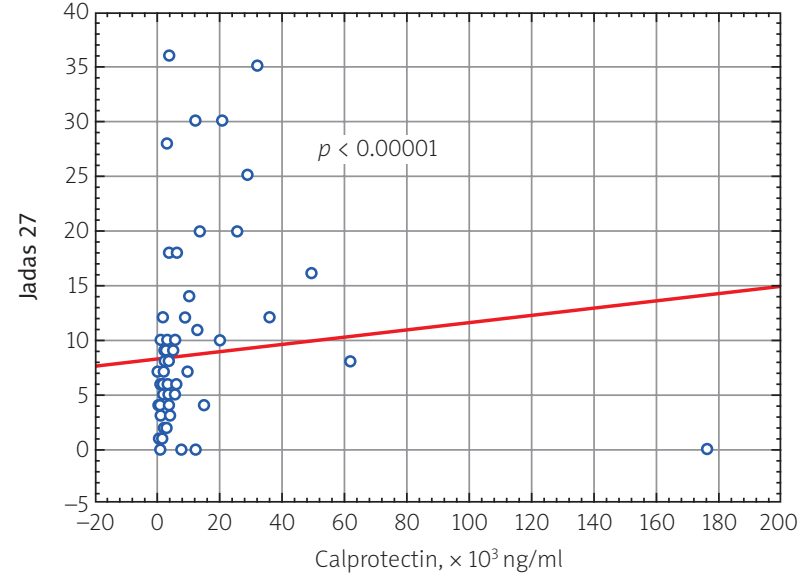

Fig. 2. Correlation relationship of blood serum calprotectin level and JADAS 27 (Juvenile Arthritis Disease Activity Score) in patients with JIA ( $p=0.000009, R=0.501128)$.

subtypes, but with other diseases manifesting with hectic fever. The most common causes of fever of unknown origin (FUO) are infectious diseases. Other FUO causes could be oncological and haemato-oncological diseases. The role of blood serum calprotectin for diagnostics of systemic-onset JIA has been investigated in many studies [10]. In the study by Frosch et al. (2009) the serum calprotectin level statistically significantly increased in patients with active systemic-onset )IA (up to 14,920 $\pm 4,030$ $\mathrm{ng} / \mathrm{ml}$ ) in comparison with healthy children of the control group $(340 \pm 70 \mathrm{ng} / \mathrm{ml})[10]$. MRP-8/MRP-14 indices in patients with acute lymphoblastic leukaemia were within the range of $650 \pm 280 \mathrm{ng} / \mathrm{ml}$, in patients with acute myeloblastic leukaemia $840 \pm 940 \mathrm{ng} / \mathrm{ml}$, and in patients with neonatal-onset multisystem inflammatory disease 2,830 $\pm 580 \mathrm{ng} / \mathrm{ml}$, which is statistically significantly lower than in patients with systemic-onset arthritis [10].

MRP-8/MRP-14 concentration in patients with systemic-onset arthritis was statistically significantly higher in comparison to patients with infectious diseases, regardless of the infection origin. At the same time, MRP-8/ MRP-14 in patients with sJIA was above 9,200 ng/ml [10]. These studies demonstrate how the scientific results can be translated for implementation in medical practice in order to differentiate SIIA. The obtained results showed a statistically significant difference in blood serum calprotectin levels of JIA patients with systemic-onset versus non-systemic disease. In patients with sJIA the median calprotectin level was $13,800 \mathrm{ng} / \mathrm{ml}$, while in patients with the non-systemic disease type it was $2,700 \mathrm{ng} / \mathrm{ml}$. Similar results were obtained in the study by Shenoi et al. (2014), where the median level of calprotectin in patients with systemic-onset JIA was $38,600 \mathrm{ng} / \mathrm{ml}$, and in patients with a non-systemic disease course it was $4,700 \mathrm{ng} / \mathrm{ml}$ [11].

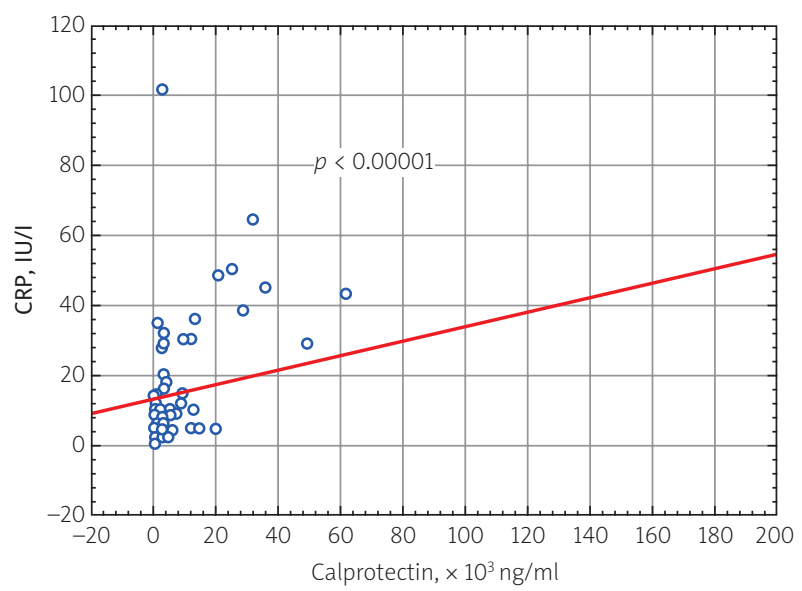

Fig. 3. Correlation relationship of blood serum calprotectin level and ESR in patients with JIA ( $p=0.000079, R=0.450954)$.

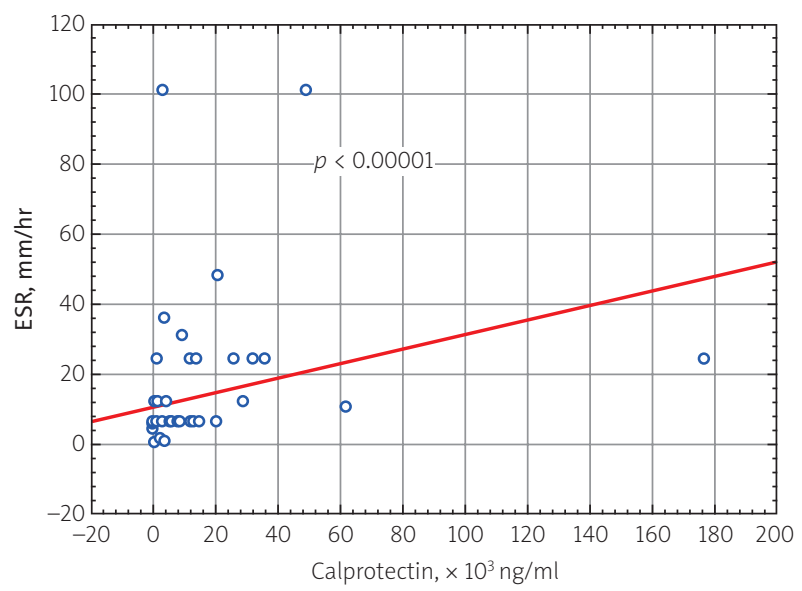

Fig. 4. Correlation relationship of blood serum calprotectin level and CRP in patients with JIA $(p=0.000058, R=0.480845)$.

The higher levels of calprotectin in patients involved in the Stanford University study can be explained by the fact that the majority of patients with sJIA had newly diagnosed disease [11]. In the study conducted at our clinic the highest calprotectin level was found in children with newly diagnosed sJIA (median 32,500 ng/ml, range: 13,800-177,000 ng/ml) (Fig. 1). In the Holtzinger et al. study [12] the highest calprotectin levels were found in blood of patients with newly diagnosed sJIA, the median being $24,750 \mathrm{ng} / \mathrm{ml}$, high levels persisted in patients with active form of the disease $(12,030 \pm 3,090 \mathrm{ng} / \mathrm{ml})$, while patients in the inactive period of SJIA had values comparable with data of healthy children from the control group (864 $\pm 86 \mathrm{ng} / \mathrm{ml})$. Serum MRP-8/MRP-14 levels in patients with SJIA from AID-NET (German registry of patients with $S J \mid A$ ) at the time of flare were statistical- 
ly significantly higher (median 9,600 ng/ml, range: 100 to $48,610 \mathrm{ng} / \mathrm{ml}$ ) in comparison with levels in these patients at disease remission (median 2,965, range: 0 to 45,390 $\mathrm{ng} / \mathrm{ml}$ ) [13].

Given that MRP-8/MRP-14 level reflects the subclinical activity of systemic-onset arthritis, this index can be used to monitor treatment effectiveness, and can be used as a therapeutic response marker. Measurement of MRP-8/ MRP-14 level provides a possibility to reveal patients with systemic-onset arthritis in the inactive stage of the disease, but with the risk of a flare [12]. It was shown that patients with SJIA in the clinical remission stage with calprotectin levels above $740 \mathrm{ng} / \mathrm{ml}$ are prone to disease flare [12]. Studies conducted in our clinic demonstrated a direct correlation of clinical and laboratory activity markers with blood serum calprotectin levels of patients with $J$ A, which indicates prospective viability of its use as a sensitive biomarker of subclinical activity of the disease.

Thus, the first results of the conducted study show that determination of serum MRP-8/MRP-14 level helps in diagnostics of systemic-onset juvenile arthritis, which is paramount for children with newly diagnosed JIA. Measurement of MRP-8/MRP-14 level can be used to monitor the subclinical activity of systemic-onset arthritis and for identification of patients with a potential risk of disease flare [2].

Measurement of MRP-8/MRP-14 in patients with systemic-onset arthritis is considered today as a new important therapeutic management instrument, which helps in diagnosis of this IIA subtype, and in decision making on termination of therapy without the risk of further exacerbation of the disease.

\section{Conclusions}

1. Blood serum calprotectin levels can be used for confirmation of diagnosis of SJIA and for monitoring the disease activity and therapy effectiveness.

2. Calprotectin levels in blood serum are highest in patients with newly diagnosed SIIA.

The author declares no conflict of interest.

\section{References}

1. Foell D, Wittkowski H, Vogl T, et al. S100 proteins expressed in phagocytes: a novel group of damage-associated molecular pattern molecules. J Leukoc Biol 2007; 81: 28-37.

2. Holzinger D, Kessel Ch, Omenetti A, et al. From bench to bedside and back again: translational research in autoinflammation. Nat Rev Rheumatol 2015; 11: 573-585.

3. Kessel C, Holzinger D, Foell D. Phagocyte-derived S100 proteins in autoinflammation: putative role in pathogenesis and usefulness as biomarkers. Clin Immunol 2013; 147: 229-241.

4. Vogl T, Tenbrock K, Ludwig S, et al. Mrp8 and Mrp14 are endogenous activators of Toll-like receptor 4, promoting lethal, endotoxin-induced shock. Nature Medicine 2007; 13: 10421049.

5. Wittkowski H, Frosch M, Wulffraat N, et al. S100A12 is a novel molecular marker differentiating systemic-onset juvenile idiopathic arthritis from other causes of fever of unknown origin. Arthritis Rheum 2008; 58: 3924-3931.

6. Foell D, Wulffraat N, Wedderburn LR. Methotrexate withdrawal at 6 vs 12 months in juvenile idiopathic arthritis in remission: a randomized clinical trial. JAMA 2010; 303: 1266-1273.

7. Swart JF, de Roock S, Prakken BJ. Understanding inflammation in juvenile idiopathic arthritis: How immune biomarkers guide clinical strategies in the systemic onset subtype. Eur J Immunol 2016; 46: 2068-2077.

8. Petty RE, Southwood TR, Manners P, et al. International League of Associations for Rheumatology classification of juvenile idiopathic arthritis: second revision, Edmonton, 2001. J Rheumatol 2004; 31: 390-392.

9. Ravelli A, Martini A. Juvenile idiopathic arthritis. Lancet 2007; 369: 767-778

10. Frosch M, Ahlmann M, Vogl T, et al. The myeloid-related proteins 8 and 14 complex, a novel ligand of toll-like receptor 4 , and interleukin-1 $\beta$ form a positive feedback mechanism in systemic-onset juvenile idiopathic arthritis. Arthritis Rheum 2009; 60: 883-891.

11. Shenoi S, Ou JN, Ni C. Comparison of biomarkers for systemic juvenile idiopathic arthritis. Pediatr Res 2015; 78: 554-558.

12. Holzinger D, Frosch M, Kastrup A, et al. The Toll-like receptor 4 agonist MRP8/14 protein complex is a sensitive indicator for disease activity and predicts relapses in systemic-onset juvenile idiopathic arthritis. Ann Rheum Dis 2012; 71: 974-980.

13. Gohar F, Husmann E, Haas PJ, et al. PReS-FINAL-2216: Biomarkers MRP8/14 and S100A12 correspond with flare and remission clinical status in Sojia patients in the AID-NET register. Pediatr Rheumatol Online J 2013; 11 (Suppl 2): 206. 